\title{
Abrasive Jet Machining Performance of Vegetable Fiber Polyester Composite and its Modelling
}

\author{
T. Premkumar, I. Siva, Sandro C Amico
}

\begin{abstract}
In this research, exploration of Abrasive Water Jet Machining (AWJM) on polyester based Curaua/basalt hybrid composite was carried out. The composites were fabricated through resin transfer molding (RTM) at a ratio of 60-40 weight percentage of matrix and fiber respectively. Experimental runs were carried out based on L27 orthogonal array considering three parameters and three levels. Further, the effect of input parameter viz., water pressure, standoff distance and feed rate on the output responses viz., kerf angle (Ta) and surface roughness (Ra) were studied. From the investigation, it is observed that stand off distance contributes a maximum in determining the results of surface roughness and kerf angle.
\end{abstract}

Keywords: Abrasive Water Jet, Hybrid Composite, Parameter Optimization

\section{INTRODUCTION}

Now a day the world moves towards friendly materials for the wealth of environmental, using reusable resources particularly in numerous engineering and automobile product, it is satisfied by fiber reinforced composites [1], many scientific researchers are suggested the effectiveness of natural sources as a reinforcement in polymer matrix composites [2]. In addition that, due to the bio- degradable nature of the natural fibre polymer composites display an incredible rate of growth in global market [3]. The last five year natural fiber usage is day by day increase in the global market, from the review of principal consultant. The advantages of natural fibers like weight of the product is less, cost of the fiber is comparatively less, density, pollution is also less at the time of production so health hazards is reduced, friendly material in all the aspect, attract the researcher to build up a new material in polymer composites. Even though natural fiber have many advantage it has some weakness also like thermal stability is low, water absorption is high for that reason, researcher transfer to hybrid composites(natural and synthetic), to overcome the above problem without compromise the mechanical properties. R. Zah et al. [4], in the automobile industry glass fiber are replaced by natural fibers for their economic, environmental and social benefits. Curaua fiber are more advantage than glass fiber due to their physical properties, cost and weight. Physical properties are nearly associating with glass fiber, cost are $50 \%$ less than the glass fiber and comparatively weight are also less than glass fiber. For the massive advantage compare to glass fiber curaua replace most of the car parts. R. V. Silva et al. [5] curaua fiber mechanical and physical properties are comparatively better than other vegetable fiber like sisal, jute and coconut fiber, at the same time this properties are very close to synthetic fiber like glass fiber.

Yan Li et al. [6] compare to other fabrication method resin transfer molding (RTM) is efficient and commercially suitable for producing a polymer reinforced composite. In this technique mechanical properties are enhanced due to the void content are reduce in the composites. José Humberto Santos Almeida Júnio et al.[7] the result shows that curaua fiber is naturally blend with synthetic fiber (glass fiber) parallel it give a good mechanical properties, the properties are equal to pure glass fiber.

V. Lopresto et al. [8], compare to synthetic fiber (glass fiber) basalt has better mechanical properties specially in 35 to $42 \%$ advanced in Young's modulus, at the same time compressive strength as well as flexural behavior also improved. Mauro Henrique Lapena et al. [9], compare to synthetic fiber (glass fiber) basalt fiber has tensile strength and in interlaminar shear stress (ILSS) weigh up to the glass fiber composites. J.Alexander et al. [10] that basalt fiber easily mingles with sisal fibers and shows excellent tensile, impact and thermal properties and concluding that the same combination of composite may use for aircraft structures.

Srinivas Athreya et al. [11], the compare to other optimization technique taguchi is provides a simple, logical, and effectual practice for enhancing the process parameters, less number of experimental result is enough compare to other techniques. S Kalirasu et al. [12] abrasive particle size plays major role and influencing the performance characteristics of abrasive water jet machining (AWJM).

\section{EXPERIMENTAL PROCEDURE}

Revised Manuscript Received on December 20, 2019.

* Correspondence Author

T. Prem kumar, Department of Mechanical Engineering, Kalasalingam Academy of Research and Education, Krishnankoil-626 126, India, Email: t.premkumar@klu.ac.in

I. Siva* , Department of Mechanical Engineering, Kalasalingam Academy of Research and Education, Krishnankoil-626 126, India, Email: isiva@klu.ac.in Sandro Amico, Department of Materials Engineering Universidade Federal do Rio Grande do Sul POA/RS, Brazil, Email: amico@ufrgs.br 
forest and the basalt fiber receive from the local market in Mumbai, Unsaturated polyester resin was purchased from Vasavibala, Chennai/TN, India Pvt limited Chennai. The curaua and basalt fiber is cut into a length of $12 \mathrm{~mm}$. During curing process, Methyl Ethyl Ketone peroxide and Cobalt napthenate were used as catalyst and accelerator

\section{B. Sample Fabrication:}

The samples are fabricated through the resin transferred moulding (RTM). The natural and synthetic Fibers are mixed and placed in the mould at the dimension of $300 \times 300 \times$ $3 \mathrm{~mm}$ with (curaua/basalt) at a weight percentage of 40 , which is then closed and clamped. With the help of compressor, an initial pressure of $0.01 \mathrm{MPa}$ was set which starts the resin transfer into the mold cavity then the pressure was increased to $0.15 \mathrm{MPa}$ and maintained till the completion of resin transfer. Then the composite were allowed to cure for a period of four hours inside the cavity.

\section{Equipment:}

The specimen is cut by Abrasive water jet machine (AWJM), cutting process is achieved by the System Dardi International Corporations (Model DIPS6-2236). The polymer composites are cut by a constant flow rate and pressure are maintained as $3.1 \mathrm{lit} / \mathrm{min}$ and $300 \mathrm{KPa}$ it is enough.

The flow rate and pressure of the abrasive is sustained at 3.1 lit/min and $300 \mathrm{KPa}$ it is sufficient enough to cut all the types of polymer, ceramic and metal matrix composite materials. The impact angle of 900 and orifice diameter of $0.7 \mathrm{~mm}$ was maintained for the machining. In this study surface roughness are measured by MITOTOYA Surf 401stylus profile meter model. The top and bottom kerf widths are measured by trinocular (Motic, Korea make) produced during the machining.

\section{EXPERIMENTAL DESIGN:}

The experimental study was conducted by a L27 orthogonal array, process parameters are mentioned in table 1. The column 1,2 and 3 are allocated to pressure (A), stand-off distance (B) and feed rate (C) respectively. The measured output reports the surface roughness and kerf angle.

TABLE I. PARAMETRIC Design

\begin{tabular}{lcccc}
\hline \multicolumn{1}{c}{ Parameters } & Unit & \multicolumn{3}{c}{ Level } \\
& & 1 & 2 & 3 \\
\hline Pressure (P) & $\mathrm{KPa}$ & 150 & 200 & 250 \\
Standoff Distance (SD) & $\mathrm{Mm}$ & 1 & 2 & 3 \\
Feed Rate(FR) & $\mathrm{mm} / \mathrm{mi}$ & 20 & 30 & 40 \\
\hline
\end{tabular}

A surface roughness of machined specimens are measured using the device of MITOTOYA Surf 401 stylus profile meter model. The surface roughness is measured along the flow of abrasive particles.

Surface finish data are taken in three different places due to the patchiness of the surface after that average value is evaluated. The surface roughness reading was taken $0.5 \mathrm{~mm}$ below and above the surface to avoid the effect of jet entry and exit, respectively. The measuring velocity and range is kept up at $0.5 \mathrm{~mm} / \mathrm{s}$ and $12.5 \mathrm{~mm}$ cut-off length.

The kerf dimension of the machined composite is measured at five different places on both side and the average of five result is noted (Maros [13]).

\section{RESULTS AND DISCUSSIONS}

To observe the influence of three independent parameters and their three levels on surface roughness (Ra) and kerf angle (Ta) of CU/BA composites we conducted the L27 orthogonal array experiments. The consequences for various mixtures of fabrication parameters were acquired, analyzed by use of the commercial software MINITAB 15. Table 2 suggests the average experimental effects of the kerf angle and surface roughness and their corresponding $\mathrm{S} / \mathrm{N}$ ratio.

TABLE II. EXPERIMENTAL RUNS AND RESULTS

\begin{tabular}{ccccccc}
\hline $\mathbf{A}$ & $\mathbf{B}$ & $\mathbf{C}$ & $\mathbf{T a}$ & $\mathbf{S} / \mathbf{N}$ & $\mathbf{R a}$ & $\mathbf{S} / \mathbf{N}$ \\
\hline 150 & 1 & 20 & 1.08 & -0.64 & 5.7 & -15.15 \\
150 & 1 & 30 & 1.86 & -5.36 & 4.6 & -13.16 \\
150 & 1 & 40 & 2.07 & -6.33 & 4.8 & -13.54 \\
150 & 2 & 20 & 1.65 & -4.35 & 5.0 & -13.97 \\
150 & 2 & 30 & 1.48 & -3.37 & 5.5 & -14.86 \\
150 & 2 & 40 & 2.13 & -6.57 & 5.0 & -13.89 \\
150 & 3 & 20 & 2.63 & -8.40 & 4.4 & -12.95 \\
150 & 3 & 30 & 2.66 & -8.50 & 5.0 & -14.06 \\
150 & 3 & 40 & 3.27 & -10.29 & 4.8 & -13.71 \\
200 & 1 & 20 & 1.65 & -4.37 & 4.3 & -12.58 \\
200 & 1 & 30 & 2.15 & -6.64 & 4.4 & -12.94 \\
200 & 1 & 40 & 3.26 & -10.26 & 4.3 & -12.72 \\
200 & 2 & 20 & 2.12 & -6.53 & 4.7 & -13.35 \\
200 & 2 & 30 & 2.34 & -7.39 & 6.7 & -16.49 \\
200 & 2 & 40 & 2.85 & -9.08 & 5.6 & -14.97 \\
200 & 3 & 20 & 2.26 & -7.09 & 5.4 & -14.56 \\
200 & 3 & 30 & 2.01 & -6.05 & 5.7 & -15.09 \\
200 & 3 & 40 & 2.45 & -7.78 & 5.7 & -15.14 \\
250 & 1 & 20 & 0.26 & 11.56 & 4.4 & -12.87 \\
250 & 1 & 30 & 2.57 & -8.19 & 4.4 & -12.77 \\
250 & 1 & 40 & 2.10 & -6.44 & 4.5 & -12.98 \\
250 & 2 & 20 & 2.21 & -6.89 & 5.1 & -14.12 \\
250 & 2 & 30 & 2.43 & -7.72 & 4.9 & -13.85 \\
250 & 2 & 40 & 2.97 & -9.44 & 5.0 & -14.06 \\
250 & 3 & 20 & 3.21 & -10.12 & 4.8 & -13.64 \\
250 & 3 & 30 & 3.49 & -10.85 & 5.2 & -14.38 \\
250 & 3 & 40 & 2.04 & -6.17 & 5.1 & -14.11 \\
\hline
\end{tabular}




\section{A. Effects of fabrication parameters on the kerf angle and surface roughness of $\mathrm{CU} / \mathrm{BA}$ composite}

The effects of machining parameters on the kerf angle of CU/BA composites can be observed and analyzed through the analysis of the $\mathrm{S} / \mathrm{N}$ ratio. Table 2 gives the $\mathrm{S} / \mathrm{N}$ ratio values inside the smaller-the-better type for the kerf angle of composites. In Table 3, the term 'rank' denotes the results of the machining parameters on the kerf angle. It is able to be seen that the "stand of distance" of the machining is the maximum influencing in the machining parameter for kerf angle accompanied via the feed rate and pressure. Similarly in the surface roughness also stand off distance is the maximum influencing in the machining parameter for feed rate followed by pressure.

TABLE III. RANK

\begin{tabular}{lcccccc}
\hline \multirow{2}{*}{ Level } & \multicolumn{3}{c}{$\mathrm{Ta}$} & \multicolumn{3}{c}{$\mathrm{Ra}$} \\
\cline { 2 - 7 } & $\mathrm{A}$ & $\mathrm{B}$ & $\mathrm{C}$ & $\mathrm{A}$ & $\mathrm{B}$ & $\mathrm{C}$ \\
\hline \multirow{2}{*}{1} & -5.98 & -4.07 & -4.09 & -13.9 & -13.1 & -13.6 \\
& 4 & 8 & 6 & 3 & 9 & 9 \\
2 & -7.24 & -6.82 & -7.12 & -14.2 & -14.4 & -14.1 \\
& 8 & 1 & 5 & 1 & 0 & 8 \\
3 & -6.03 & -8.36 & -8.04 & -13.6 & -14.1 & -13.9 \\
& 3 & 6 & 5 & 5 & 9 & 1 \\
Delta & 1.265 & 4.288 & 3.949 & 0.57 & 1.21 & 0.49 \\
Rank & 3 & 1 & 2 & 2 & 1 & 3 \\
\hline
\end{tabular}

The main influence plots for approach and $\mathrm{SN}$ ratios as received from Minitab 17 software program are given in Fig 1(a) and (b) the reference line drawn is showing the average mean for overall response. From the main impact plots it's far clean that the surface roughness will be supreme at level 1 at $150 \mathrm{Kpa}$ pressure, level 1 for standoff distance $1 \mathrm{~mm}$, level 1 for feed rate at $20 \mathrm{~mm} / \mathrm{min}$. The smaller is better first-class characteristic has been set for SN ratio plot. It is easy to verify the most fulfilling parameter tiers by the main results plot for approach.

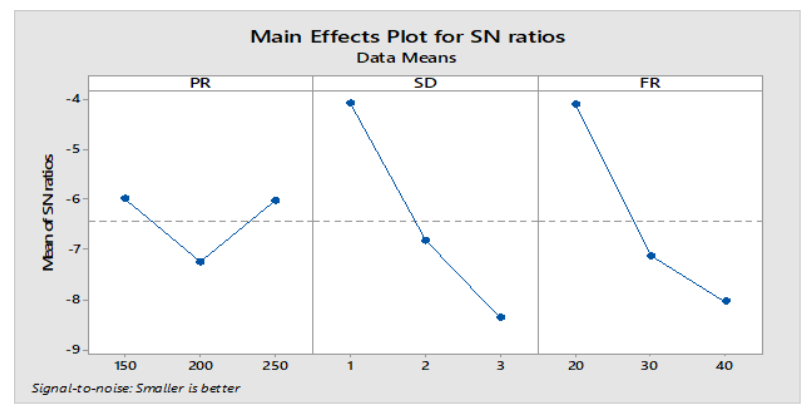

FIG I. (a) Mean effects plot for kerf angle

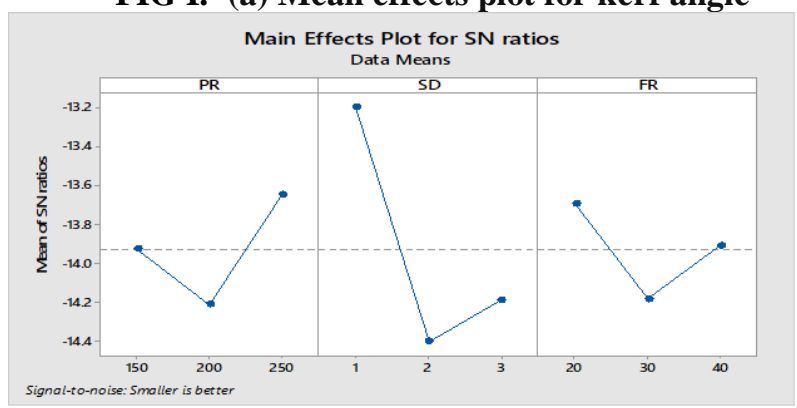

FIG II. (b) Mean effects plot for surface roughness

The finest situations for the surface roughness can be recognized. It may be experimental that the growth of the pressure and feed rate increase the surface roughness. It was the observed that the surface roughness decreased at the same cutting parameters with increase in stand of distance.as a result, with proper choice of process parameters, it is possible to viable to decrease the surface roughness.

The viable contribution of machining parameters on the responses viz., kerf angle and surface roughness were studied and the possible optimum combinations of the machining parameter was found by relating $\mathrm{S} / \mathrm{N}$ ratio. The ANOVA was carried out to identify the influence of machining parameters on output responses viz., the kerf angle and surface roughness and the same depicted on Table 4 and Table 5 respectively.

From the ANOVA on Table 4, it was found that the standoff distance $(33.08 \%)$ have an utmost impact on kerf angle. In addition to the standoff distance, feed rate contributes (25.36\%) comparatively less and pressure contribute $(4.9 \%)$ least on the kerf angle.

TABLE IV. ANOVA- KERF ANGLE

\begin{tabular}{cccccc}
\hline & $\begin{array}{c}\text { sum of } \\
\text { squares }\end{array}$ & df & Variance & f value & contribution \\
\hline A & 0.4128 & 2 & 0.2064 & 1.0685 & 4.9744 \\
B & 2.7458 & 2 & 1.3729 & 7.1073 & 33.0869 \\
C & 2.1049 & 2 & 1.0524 & 5.4483 & 25.3641 \\
AxB & 2.4826 & 4 & 0.6206 & 3.2129 & 14.9576 \\
AxC & 1.1987 & 4 & 0.2996 & 1.5514 & 7.2223 \\
BxC & 2.3891 & 4 & 0.5972 & 3.0920 & 14.3944 \\
erro & & & & & \\
r & 1.5453 & 8 & 0.1931 & & \\
total & 12.8796 & 26 & 4.1494 & & \\
& & & & & \\
\end{tabular}

From table 5, it has been seen that standoff distance was a predominant parameter persuading the surface roughness (43.77\%). Additionally it is also observed that the pressure and feed rate have an impact on surface roughness at a percentage contribution of $12.5 \%$ and $7.34 \%$ respectively.

TABLE V. ANOVA-SURFACE ROUGHNESS

\begin{tabular}{|c|c|c|c|c|c|}
\hline & sum of squares & df & Variance & fvalue & contibution \\
\hline A & 0.6489 & 2 & 0.3244 & 2.2121 & 12.5188 \\
\hline$B$ & 2.2689 & 2 & 1.1344 & 7.7348 & 43.7728 \\
\hline C & 0.3822 & 2 & 0.1911 & 1.3030 & 7.3741 \\
\hline$\underline{A x B}$ & 2.0956 & 4 & 0.5239 & 3.5720 & 20.2144 \\
\hline$\underline{A x C}$ & 0.6489 & 4 & 0.1622 & 1.1061 & 6.2594 \\
\hline BxC & 1.0222 & 4 & 0.2556 & 1.7424 & 9.8607 \\
\hline emior & 1.1733 & 8 & 0.1467 & & \\
\hline total & 8.24 & 26 & 2.5917 & & \\
\hline
\end{tabular}




\section{CONCLUSION}

The machining studies of basalt/curaua fiber reinforced polyester hybrid composite using Abrasive Water Jet Machining is positively done and the inferences are listed.

$>$ The Roughness average (Ra) monotonically increases with an incremental variation in the input process parameters. However, the standoff distance predominantly affecting the $\mathrm{Ra}$ and the percentage contribution found to be $43.77 \%$.

$>$ The maximum kerf angle has been produced at an optimum combination at a level of process parameters, 3-1-1 representing standoff distance, water pressure, and traverse speed respectively.

$>$ The process parameters viz., standoff distance have major influence followed by pressure on kerf angle and the percentage of influence by statistical technique was found to be $33.08 \%$ and $25.35 \%$ respectively.

\section{REFERENCES}

1. MR, Sanjay, and Suchart Siengchin. "Natural fibers as sustainable and renewable resource for development of eco-friendly composites: a comprehensive review." Frontiers in Materials 6 (2019): 226.

2. Mohammed, Layth, MOHAMED NM Ansari, Grace Pua, Mohammad Jawaid, and M. Saiful Islam. "A review on natural fiber reinforced polymer composite and its applications." International Journal of Polymer Science 2015 (2015).

3. Siakeng, Ramengmawii, Mohammad Jawaid, Hidayah Ariffin, S. M. Sapuan, Mohammad Asim, and Naheed Saba. "Natural fiber reinforced polylactic acid composites: A review." Polymer Composites 40, no. 2 (2019): 446-463.

4. Zah, Rainier, R. Hischier, Alcides Lopes Leão, and I. Braun "Curauá fibers in the automobile industry-a sustainability assessment." Journal of cleaner production 15, no. 11-12 (2007): $1032-1040$.

5. Silva, R. V., and E. M. F. Aquino. "Curaua fiber: a new alternative to polymeric composites." Journal of reinforced plastics and composites 27, no. 1 (2008): 103-112.

6. Li, Yan. "Processing of sisal fiber reinforced composites by resin transfer molding." Materials and manufacturing processes 21, no. 2 (2006): 181-190

7. Almeida Jr, José Humberto Santos, Sandro Campos Amico, Edson Cocchieri Botelho, and Franco Dani Rico Amado. "Hybridization effect on the mechanical properties of curaua/glass fiber composites." Composites Part B: Engineering 55 (2013): 492-497.

8. Lopresto, V., Claudio Leone, and I. De Iorio. "Mechanical characterisation of basalt fibre reinforced plastic." Composites Part B: Engineering 42, no. 4 (2011): 717-723.

9. Lapena, Mauro Henrique, and Gerson Marinucci. "Mechanical characterization of basalt and glass fiber epoxy composite tube." Materials Research 21, no. 1 (2018).

10. Alexander, J., and SJ Elphej Churchill. "Mechanical Characterization of Baslat Based Natural Hybrid Composites for Aerospace Applications." In IOP Conference Series: Materials Science and Engineering, vol. 197, no. 1, p. 012008. IOP Publishing, (2017).

11. Athreya, Srinivas, and Y. D. Venkatesh. "Application of Taguchi method for optimization of process parameters in improving the surface roughness of lathe facing operation." International Refereed Journal of Engineering and Science 1, no. 3 (2012): 13-19.

12. Kalirasu, S., N. Rajini, J. T. Winowlin Jappes, M. Uthayakumar, and S. Rajesh. "Mechanical and machining performance of glass and coconut sheath fibre polyester composites using AWJM." Journal of Reinforced Plastics and Composites 34, no. 7 (2015): 564-580.
13. Maros, Zsolt. "Energy approach of the taper at abrasive waterjet cutting." Production Processes and Systems 6, no. 1 (2013): 89-96.

\section{AUTHORS PROFILE}

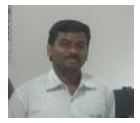

Mr. T. Premkumar is currently working as Assistant Professor in the Department of Mechanical Engineering, Kalasalingam Academy of Research and Education, Anand nagar, Krishnankoil-62612., India. He has 8 years teaching as well as research experience. He is a Member of Indian Society for Technical Education. His areas of interest are polymer composite, materials characterization, tribology.

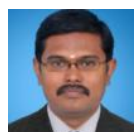

Dr. I. Siva is currently working as Professor in the Departmen of Mechanical Engineering, Kalasalingam Academy of Research and Education, Anand nagar, Krishnankoil-626126, India He has 15 years teaching as well as research experience. He is a reviewer more than 50 reputed journals $\mathrm{He}$ is a Member of Indian Society for Technical Education. His area of interest are polymer composite, materials characterization, tribology,FML

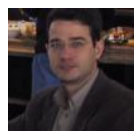

Sandro Amico is currently working as Professor in the Department of Materials Engineering Universidade Federal do Rio Grande do Sul POA/RS, Brazil, He has more than 15 years teaching as well as research experience. He is a reviewer more than 20 reputed journals. He has published more than 400 international journals. His areas of interest are polymer composite, materials characterization, tribology. 